\title{
The Competency Movement in Psychiatric Education: 2020 View
}

\author{
Anthony P. S. Guerrero ${ }^{1} \cdot$ Rashi Aggarwal ${ }^{2} \cdot$ Richard Balon $^{3} \cdot$ Eugene V. Beresin ${ }^{4} \cdot$ Mary K. Morreale $^{3}$. \\ John Coverdale ${ }^{5} \cdot$ Alan K. Louie $^{6} \cdot$ Adam M. Brenner $^{7}$
}

Accepted: 22 October 2020 / Published online: 29 October 2020

(C) Academic Psychiatry 2020

It has now been several years since the Psychiatry Milestones, part of the Next Accreditation System (NAS) of the Accreditation Council for Graduate Medical Education (ACGME), were implemented. There has been a recent effort to revise and simplify the Milestones in all disciplines in general and in psychiatry in particular [1]. According to the Psychiatry Milestones 2.0 group [1], the new version of Psychiatry Milestones is harmonized and is narrower in scope, and the number of milestones has been reduced to 22 from 21 .

In an earlier editorial [2], we advocated for a balance between "the social contract of ensuring that psychiatry graduates meet standards of competency" and "overregulation of education and proliferation of benchmarks faster than can be meaningfully inspired, taught, and measured." We also posed the following questions:

- Could competencies be simplified towards basic skills and practice behaviors that will inspire confidence in healthcare providers and receivers alike?

- Could the burden of inventing and implementing competency-based programs be reduced by sharing and disseminating evidence-based training modules...?

Anthony P. S. Guerrero

GuerreroA@dop.hawaii.edu

1 University of Hawai'i John A. Burns School of Medicine, Honolulu, HI, USA

2 Rutgers New Jersey Medical School, Newark, NJ, USA

3 Wayne State University, Detroit, MI, USA

4 Harvard Medical School, Boston, MA, USA

5 Baylor College of Medicine, Houston, TX, USA

6 Stanford University, Stanford, CA, USA

7 University of Texas Southwestern Medical Center, Dallas, TX, USA
- In a competencies-focused environment, is enough focus given to nurturing the supervisory and mentoring relationships that motivate and inspire competence?

Thus, the competencies simplification we sought in the previous editorial [2] has been moving in the right direction. This journal has published a number of articles, including several in the December 2020 issue, that attempted to answer the three questions posed above or related questions. The authors aimed to advance our understanding of what it takes to "sustainably produce competent psychiatrists and optimal health care outcomes" and to illustrate other countries' experiences with the competency-based movement.

In the December 2020 issue of Academic Psychiatry, two papers from Canada $[3,4]$ discuss the importance of graspable and relevant competencies. They provide a helpful introduction to the Competency By Design (CBD) approach of the Royal College of Physicians and Surgeons of Canada (RCPSC), which incorporates Entrustable Professional Activities (EPAs) and Milestones. Fage and colleagues [4] described the EPAs and milestones-formulated by a resident working group within the University of Toronto Psychiatry Program - associated with clinical on call experiences. The authors appropriately described the challenge of "calibrating the tension between granularity and breadth..." as "a system with too many EPAs becomes unwieldy, and one with too few becomes reductionist." Danielwitz and colleagues [3] provide detailed competencies, "reflective of what residents actually do," in neurostimulation, which represents a "procedure" in the classical sense. They cited, as guiding principles, the need for clarity, applicability, reliability, and validity.

We note that the heart and soul of psychiatric practice is, indeed, an intricate "procedure" that involves establishing a therapeutic alliance, taking a detailed history, performing a thorough mental status exam, developing a biopsychosocial formulation, and developing a patient-centered treatment plan and that (distinct from surgical procedures) is done in 
collaboration with (rather than "to") the patient and that ideally is assessed qualitatively.

Lloyd and colleagues [5] and Silberman and colleagues [6] addressed a very essential question: how exactly do programs make concrete the task of translating real-life supervision and assessments into the required quantitative milestone ratings? Lloyd and colleagues [5] convened program directors and associate program directors across three distinct programs in a mock clinical competency committee (CCC) format to assign milestones, based on annual assessments, to a second-year resident and a third-year resident. They studied the reliability of the processes and provided various recommendations including maximizing the number of end-of-rotation assessments, utilizing and developing other assessment tools for competencies other than patient care and medical knowledge, and using end-of-rotation evaluations with Clinical Skills Examinations (CSEs) to support CCC decisions and to increase the reliability of assessments. Silberman and colleagues [6] very aptly noted, "The Milestones Project of the Accreditation Council for Graduate Medical Education (ACGME) parses psychiatric competency into multiple specific areas of knowledge and skill, but offers no procedures for assessing them." They therefore developed and tested the psychometric properties of a casebased, multiple-choice test focused on data gathering and interpretation, diagnosis, hypothesis generation and testing, and treatment planning. Their novel test of formulation and treatment planning may be one of many potentially helpful tools in evaluating residents' reasoning skills.

Sullivan and colleagues [7] described their project focused on teaching psychiatric formulation, which is a key patient care competency. They assessed faculty's teaching in this area, engaged them in an interactive demonstration of teaching approaches, and invited residents to observe the faculty learn. They concluded that "residents need direct and regular instruction in the psychiatric case formulation, a skill that a majority of them judge to be difficult" and that "faculty, though perhaps themselves proficient in formulation, lack direct education in making this skill accessible to residents." We hope that there will be further development of user-friendly modules to develop faculty's proficiency and comfort in teaching core competencies in our specialty.

Finally, Etxeanda-Pradera and colleagues [8] from Spain provided the background that, within the European Union (EU), undergraduate psychiatric education in medical schools is set by a common framework (the Bologna Process), while postgraduate training to become a psychiatrist is not quite as uniform. They presented a Strengths/Weaknesses/ Opportunities/Threats (SWOT) analysis of current psychiatry training, which is currently reliant on "tutor psychiatrists, who are responsible for planning, management, supervision, and evaluation" of the whole residency training process, and the potential roles of a locally contextualized competency-based framework. We hope we will have the opportunity to publish other international papers describing the cultural, interperson$\mathrm{al}$, and mentorship-focused aspects of adopting competencies.

Obviously, in the midst of this global SARS-CoV-2/ COVID-19 pandemic, it is understandable that many educational programs have remained on "survival mode," with limited time to proactively plan and evaluate competency-based educational innovations. One positive outcome of the pandemic has been to transform our educational culture from almost completely in-person to mostly virtual education, and even to enable a degree of ease with the latter. This change opens new avenues for programs to pool their resources and facilitates the dissemination of evidence-based modules for learning and evaluation (including evaluations of clinical skills) across programs. Also, notwithstanding the profound stresses and far-reaching disruptions inflicted by the pandemic, many educational programs have fortunately continued to discover new opportunities for teaching and training based on a foundation of caring faculty, established psychiatric clinical learning environments, and value placed on training and workforce development.

As the articles in this issue of the journal show, progress has been made in addressing the questions raised at the beginning of this editorial. However, much work is still to be done. For example, in order for certain milestones to be meaningful and widely applicable, there has to be some degree of interrater consistency and common ways to measure progress across institutions. We also need to continue to identify and hone the list of basic skills and practice behaviors (EPAs) that are associated with the ACGME milestones and that "inspire confidence in healthcare providers and receivers alike."

But also, as we note above, the essence of psychiatric competency is the ability to establish relationships, question observations, improve skills, and continuously collaborate with patients in treatment. Not all treatments are $100 \%$ effective, and what matters is the movement to change behavior and patients' overall sense of well-being, adaptability, and functioningwhich are often more ideally measured qualitatively (e.g., by evaluators who observe interviews or narrative discussions and who achieve consensus) rather than quantitatively. If we were to move to a more qualitative appraisal of outcomes, paradigms of good narratives (histories) and ways of conceptualizing patients, contexts, environmental variables could be disseminated nationally as prototypes. Heeding the warning of Peabody [9], we need to ensure that our trainees do not become too "scientific" to the point that they "do not know how to take care of patients."

Furthermore, as we move forward with using the competency-based model to teach and supervise our residents, we have to ensure that we also continue to prioritize "the supervisory and mentoring relationships that motivate and inspire competence." Louie et al. [10] pointed out, quite presciently, that, even in a competency-based training framework, because "in much of medicine evidence-based practices are yet to be defined... we need to have trained physicians... go beyond technically prescribed skills and seek creative 
solutions, while exercising common sense and precaution." Ultimately, education reforms need to produce "better" psychiatrists, as indicated by accurate measures of real-life outcomes.

We do not yet have positive answers to the questions we raised in our previous editorial [2] recited at the beginning of this editorial. Thus, our specialty must continue to simplify and hardwire the task of training and assessing competencies according to best practices. We need to do so in order to ensure that the psychiatric workforce is well prepared to meet the growing demands of a pandemic-affected community andvery importantly - to ensure that front-line educators can have the time and space to optimally keep trainees, teachers, and patients safe. We hope that Academic Psychiatry can serve as a catalyst for inspiration through the creative development, discussion, and dissemination of these best practices.

\section{Compliance with Ethical Standards}

Disclosures On behalf of all authors, the corresponding author states that there is no conflict of interest.

\section{References}

1. Macaluso M, Kinzie M, Cowley D, et al. Acad Psychiatry. 2020. https://doi.org/10.1007/s40596-020-01275-0.
2. Guerrero APS, Beresin EV, Balon R, Brenner AM, Louie AK, Coverdale JH, et al. The competency movement in psychiatric education. Acad Psychiatry. 2017;41(3):312-4.

3. Danilewitz M, Ainsworth NJ, Liu C, Vila-Rodriguez F. Towards competency-based medical education in neurostimulation. Acad Psychiatry. 2020. https://doi.org/10.1007/s40596-020-01195-z.

4. Fage B, Alldred T, Levitt S, Abate A, Fefergrad M. Competency on call: resident driven learning objectives for competency-based medical education. Acad Psychiatry. 2020. https://doi.org/10.1007/ s40596-019-01178-9.

5. Lloyd RB, Park YS, Tekian A, Marvin R. Understanding assessment systems for clinical competency committee decisions: evidence from a multisite study of psychiatry residency training programs. Acad Psychiatry. 2019. https://doi.org/10.1007/s40596019-01168-X.

6. Silberman EK, Ramesh S, Adler D, Sargent J, Moore T, Blanco M. Assessing residents' skills in psychiatric reasoning: the tufts test of formulation and treatment planning. Acad Psychiatry. 2020. https:// doi.org/10.1007/s40596-020-01234-9.

7. Sullivan M, Walton MF, Auchincloss EL, Penzner JB. Teaching psychiatric formulation to residents and faculty. Acad Psychiatry. 2020. https://doi.org/10.1007/s40596-020-01222-z.

8. Etxeandia-Pradera JI, Martinez-Uribe D, Bellver-Pradas F, Gonzalez-Piqueras JC, Aguilar EJ. The challenge of introducing competency-based psychiatry training in Spain. Acad Psychiatry. 2020. https://doi.org/10.1007/s40596-020-01221-0.

9. Peabody FW. The care of the patient. JAMA. 1927;88:877-82.

10. Louie AK, Coverdale J, Roberts LW. Competency-based training: where will it lead us? Acad Psychiatry. 2004;28(3):161-3.

Publisher's Note Springer Nature remains neutral with regard to jurisdictional claims in published maps and institutional affiliations. 